\title{
Burnout and Paths to Turnover Intentions among South African Sport Coaches
}

\author{
Alliance Kubayi ${ }^{1}$ \\ Affiliations: 'Tshwane University of Technology, Department of Sport, Rehabilitation and Dental Sciences, Pretoria, \\ South Africa
}

Correspondence: A. Kubayi, Tshwane University of Technology, Department of Sport, Rehabilitation and Dental Sciences, Pretoria, 0001, Republic of South Africa. E-mail: kubayina@tut.ac.za

ABSTRACT This study investigated burnout and turnover intentions among 119 South African sport coaches (78 males and 38 females) aged 18 to 64 years $(\mathrm{M}=30.28, \mathrm{SD}=9.83$ years), who were recruited to participate in the study. Data were collected using the Maslach Burnout Inventory and Turnover Intentions Questionnaire. The results showed that sport coaches reported low levels of emotional exhaustion and personal accomplishment, with the exception of depersonalization, demonstrating that sport coaches were less burned out. Of the three subscales of burnout, the highest significant correlation was observed between emotional exhaustion and turnover $(\mathrm{r}=.227, p<.01)$. The practical implications of the findings are discussed, and recommendations for future research are provided.

KEY WORDS burnout, sport, coaches, turnover intentions

@MJSSMontenegro

BURNOUT AND PATHS TO TURNOVER INTENTIONS

http://mjssm.me/?sekcija=article\&artid=162

\section{Introduction}

Sport coaching is a very demanding and stressful profession (Koustelios, 2010). This is because the role of a sport coach has evolved, and coaching is steadily moving towards professionalization. Unlike in the past, when sport coaches were required to impart skills and knowledge to their athletes, today they are often also expected to perform a myriad of duties, including being a sport psychologist, planner, role model, organizer, disciplinarian, confidant, and motivator, to mention just a few. Sport coaches are expected to conduct practice sessions in preparation for games, motivate athletes to achieve, interact with the public and press, and often go on the road to scout opponents (Wuest \& Fisette, 2012), while also being responsible for improving and expanding their own capabilities on an ongoing basis to fully meet the needs of the athletes they serve (International Council for Coaching Excellence and the Association of Summer Olympic International Federations, 2012). Additionally, sport coaches need to keep abreast of the latest technology in sport in order to improve their athletes' performances.

These and many more demands, coupled with the pressure to win, impose considerable stress on coaches. Sometimes, the pressure to do it all and do it well can be overwhelming for coaches (Wuest \& Fisette, 2012), thereby frustrating them to the extent that they feel they have to leave the coaching profession prematurely. Although some researchers (e.g. Everhart \& Chelladurai, 1998; Kamphoff, 2010; Kubayi, 2015; Kubayi, Coopoo, \& Morris-Eyton, 2015) have found that coaches leave the profession due to factors such as unfavourable working hours, low salary, interference from management, time constraints, job insecurity, inadequate resources, and parental pressure, Wuest and Fisette (2012) and Raedeke (2004) are of the opinion that most coaches stop coaching because of a desire for a career change, disenchantment with the profession, and most importantly, as a consequence of burnout. Burnout can be defined as a psychological syndrome of emotional exhaustion, depersonalization, and reduced personal accomplishment that can occur among individuals who work with people in some capacity (Maslach, Jackson, \& Leiter, 1997).

Burnout has drawn increasing interest from researchers in a number of disciplines (Raedeke, Granzyk, \&

Received: March 022018 | Accepted after revision: April 112018 | First published online: September 012018

(c) 2018 by the author(s). License MSA, Podgorica, Montenegro. This article is an open access article distributed under the terms and conditions of the Creative Commons Attribution (CC BY).

Conflict of interest: None declared. 
Warren, 2000). Consequently, this has resulted in studies investigating the prevalence of burnout among sport coaches (Hjalm, Kentta, Hassmenan, \& Gustafsson, 2007). However, according to Kelley, Eklund, and Ritter-Taylor (1999), early studies on the subject of burnout have sought to examine demographic (e.g. gender, marital status, coaching experience, individual or team sports), dispositional (e.g. leadership style) and situational variables (e.g. role ambiguity, work overload) (e.g. Caccese \& Mayerberg, 1984; Dale \& Weinberg, 1989; Pastore \& Judd, 1993). Despite the significant contribution of such studies, turnover has received surprisingly little attention in research on coach burnout (Kilo \& Hassmen, 2016).

Consequently, there is a lack of information about the role of burnout in association with turnover intentions (Zhang \& Feng, 2011). Such research is important because the repercussions of burnout are numerous and often quite severe, affecting coaches as well as athletes. Furthermore, insomnia, hypertension, ulcers, and other stress-related symptoms may manifest themselves in burned-out sport coaches (Wuest \& Fisette, 2012). Burnout is also associated with low productivity, absenteeism, deterioration of health and employee turnover. Workers (i.e., coaches) who are burned out are more likely to remain in their current jobs but will be dysfunctional or ineffective, or seek another profession, or leave the profession entirely (De Croon, Sluiter, Blonk, Broersen, \& Frings-Dresen, 2004; Gencay \& Gencay, 2011; Wuest \& Fisette, 2012). Similarly, coach turnover is of great concern because it forces organizations and clubs to use already limited resources to recruit new coaches, rather than developing existing ones (Sport Coach UK, 2013).

Therefore, this study seeks to fill the gap in the literature by investigating burnout and intentions to leave the coaching profession among South African coaches. The results of this study could provide a better understanding of the early detection of potential coach turnover and possible strategies to prevent it (Leiter \& Maslach, 2009). Specifically, the aims of this study were twofold: (1) to examine the prevalence of burnout among sport coaches, and (2) to ascertain the relationship between burnout and turnover intentions among sport coaches.

\section{Methods}

Participants

The sample comprised 119 sport coaches (78 males and 38 females) aged between 18 and 64 years $(\mathrm{M}=30.28$, $\mathrm{SD}=9.83$ years). The participants represented four sports: rugby $(\mathrm{n}=58)$, netball $(\mathrm{n}=24)$, cricket $(\mathrm{n}=24)$, and hockey $(n=12)$. The participants were purposively recruited to participate in this study through their sport federations.

\section{Measures}

\section{Maslach Burnout Inventory}

Coach burnout was measured using the Maslach Burnout Inventory (MBI) (Maslach \& Jackson, 1986). The MBI measures three subscales of burnout: emotional exhaustion, depersonalization, and personal accomplishment. The emotional exhaustion subscale contains nine items (e.g. "I feel frustrated by my job"), the personal accomplishment subscale consists of eight items (e.g. "I feel very energetic"), and the depersonalization subscale comprises five items (e.g. "I worry that this job is hardening me emotionally"). All items were anchored on a 7-point Likert scale, ranging from 0 (never) to 6 (every day).

\section{Turnover Intentions Questionnaire}

Three items developed by Meyer, Allen, and Smith (1993) and adapted by Kilo and Hassmen (2016) were used to assess sport coaches' intentions to leave the coaching profession. Examples of these items included "I plan to leave the coaching profession in the next year due to job stress", "I think a lot about quitting coaching because of job stress", and "I am actively searching for a position outside of coaching because of job stress". All items were scored on a 5-point scale ranging from 1 (strongly disagree) to 5 (strongly agree).

\section{Data collection and analysis}

Prior to data collection, this study received full ethical clearance from the Faculty of Science Research Ethics Committee of the Tshwane University of Technology, South Africa. Informed consent was sought from the participants after the purpose of the study was explained. The questionnaires were administered to the participants in hand and collected once completed. Data analyses were performed using the Statistical Package for the Social Sciences (SPSS) version 23. Descriptive statistics such as means, standard deviations and frequencies were used to analyse the data. Correlation coefficients were also computed to assess the relationships between the three dimensions of burnout and turnover intentions among sport coaches.

\section{Results}

Table 1 shows the descriptive statistics of the burnout subscales according to demographic variables. Female coaches reported higher levels of emotional exhaustion $(M=20.24, S D=11.15)$, while male coaches reported a high score of personal accomplishment $(\mathrm{M}=35.06, \mathrm{SD}=8.34)$ and depersonalization $(\mathrm{M}=7.73, \mathrm{SD}=6.38)$. Findings further showed that the coaches' emotional exhaustion seemed to increase with age and coaching experience. Additionally, experienced coaches (6-10 years) scored high on emotional exhaustion $(\mathrm{M}=21.28$, $\mathrm{SD}=14.71)$ and depersonalization $(\mathrm{M}=12.67, \mathrm{SD}=7.39)$ than less experienced $(1-5$ years $)$ and more experienced coaches (11+ years). 
TABLE 1 Means and Standard Deviations of Burnout Subscales for Demographic Variables

\begin{tabular}{lclll} 
Variable & $\mathbf{n}$ & $\begin{array}{l}\text { Emotional exhaustion } \\
\mathbf{M}(\mathbf{S D})\end{array}$ & $\begin{array}{l}\text { Personal } \\
\text { accomplishment } \\
\mathbf{M} \text { (SD) }\end{array}$ & $\begin{array}{l}\text { Depersonalization } \\
\mathbf{M} \text { (SD) }\end{array}$ \\
\hline $\begin{array}{l}\text { Sex } \\
\quad \text { Male }\end{array}$ & 78 & $14.27(10.89)$ & $35.06(8.34)$ & $7.73(6.38)$ \\
$\quad \begin{array}{l}\text { Female } \\
\text { Age categories }\end{array}$ & 38 & $20.24(11.15)$ & $33.55(10.28)$ & $7.55(6.57)$ \\
$\quad$ 18-29 years & 65 & $14.31(10.51)$ & $35.42(9.45)$ & $6.20(5.76)$ \\
30-39 years & 26 & $18.35(13.30)$ & $33.77(7.24)$ & $9.62(7.58)$ \\
40+ & 25 & $19.00(10.37)$ & $33.20(9.56)$ & $9.48(5.95)$ \\
Coaching experience & & & & \\
1-5 years & 81 & $14.75(10.10)$ & $34.80(8.92)$ & $6.57(5.94)$ \\
6-10 years & 18 & $21.28(14.71)$ & $34.11(9.90)$ & $12.67(7.39)$ \\
11+ & 17 & $17.88(11.44)$ & $33.94(8.92)$ & $7.65(5.18)$ \\
\hline
\end{tabular}

Table 2 displays the MBI subscales' norms set by Maslach, Jackson, and Leiter (1996) and the means of coaches' three dimensions of burnout. In comparison to the norms, the results of the present study indicated that coaches scored relatively low on emotional exhaustion and personal accomplishment, with the exception of depersonalization, thus suggesting that coaches were less burned out.

\begin{tabular}{|c|c|c|c|}
\hline Variable & $\begin{array}{l}\text { Emotional exhaustion } \\
M \quad \text { (SD) }\end{array}$ & $\begin{array}{l}\text { Personal accomplishment } \\
\text { M }\end{array}$ & $\begin{array}{l}\text { Depersonalization } \\
\text { M (SD) }\end{array}$ \\
\hline \multicolumn{4}{|l|}{ MBI norms } \\
\hline Male & $19.86(10.47)$ & 36.29 (6.76) & 7.43 (5.99) \\
\hline Female & $20.99(10.66)$ & $36.50(6.56)$ & $7.02(6.34)$ \\
\hline \multicolumn{4}{|c|}{ Present study } \\
\hline Male & 14.27 (10.89) & $35.06(8.34)$ & $7.73(6.38)$ \\
\hline Female & $20.24(11.15)$ & $33.55(10.28)$ & $7.55(6.57)$ \\
\hline
\end{tabular}

Correlation coefficients for demographic variables, the three burnout subscales, and turnover intentions are shown in Table 3. Among the three subscales of burnout, the highest correlation was found between turnover intention and emotional exhaustion $(\mathrm{r}=.227, p<.01)$, and the least negative relationship with depersonalization $(\mathrm{r}=-.195, p<.05)$. However, there was a strong positive correlation between emotional exhaustion and depersonalization $(\mathrm{r}=.615, p<.01)$.

TABLE 3 Correlations Between Demographic Variables, Burnout Subscales and Turnover Intention

\begin{tabular}{|c|c|c|c|c|c|c|}
\hline Variable & 1 & 2 & 3 & 4 & 5 & 6 \\
\hline Age & - & & & & & \\
\hline Coaching experience & $.627^{* *}$ & & & & & \\
\hline Emotional exhaustion & .157 & .172 & & & & \\
\hline Personal accomplishment & -.050 & .070 & $-.250^{* *}$ & & & \\
\hline Depersonalization & $.197^{*}$ & .149 & $.615^{* *}$ & -.175 & & \\
\hline Turnover intentions & $.224^{*}$ & .033 & $.227^{* *}$ & $.212^{*}$ & $-.195^{*}$ & - \\
\hline
\end{tabular}

Note: ${ }^{*} \mathrm{p}<.05 ;{ }^{* *} \mathrm{p}<.01$

\section{Discussion}

The primary aim of this study was to examine the prevalence of burnout among coaches. Female coaches reported higher scores of perceived burnout on the emotional exhaustion subscale than male coaches did. This finding is consistent with that of Pastore and Judd (1993). Although the reasons for high levels of emotional exhaustion among female coaches in the current study are not clear, Caccese and Meyerberg (1984) and Pastore and Judd (1993) speculated that female coaches tend to stress themselves excessively in order to prove their worth. Another possible explanation could be that female coaches are expected to perform coaching responsibilities while also fulfilling duties outside work, such as being a good wife, mother, and so forth. Thus, future studies should focus on investigating strategies that could reduce high burnout levels encountered by female coaches. This is very important for women because the proportion of female coaches is declining, and 
they are leaving the coaching profession sooner than their male counterparts do. Such studies may provide strategies to encourage female coaches to remain in the profession for longer periods (Pastore \& Judd, 1993).

The results of this study further showed that coaches' emotional exhaustion increased with age and years of coaching experience. This finding contradicts those of Pastore and Judd (1993) and Weinberg and Gould (2007), who reported that emotional exhaustion decreased with age and coaching experience. This result could indicate that burnout occurs over the course of time; therefore, older and experienced coaches could have accumulated it (Dale \& Weinberg, 1989). In comparison to MBI norms (see Table 2) established by Maslach et al. (1996), both male and female coaches reported lower levels of emotional exhaustion and personal accomplishment and higher levels of depersonalization. This is a positive finding, given the most publicity concerning the higher levels of stress associated with the coaching profession (Dale \& Weinberg, 1989; Frey, 2007; Kubayi, Toriola, \& Didymus, 2018). However, this does not mean that burnout is not a problem in coaching. Rather, researchers have to be sensitive to the situational and personal variables that may be related to or predictive of burnout (Dale \& Weinberg, 1989). Overall, both male and female coaches displayed lower scores of perceived burnout. A plausible reason for this finding is that coaches who feel extremely high levels of burnout have already left coaching (Weinberg \& Gould, 2007). Consequently, this leaves only the "survivors" who have developed adequate coping skills to handle the extra pressure in coaching (Hjalm et al., 2007).

The secondary aim of the study was to ascertain the relationship between burnout and turnover intentions among sport coaches. Emotional exhaustion was the most strongly related subscale of burnout that significantly correlated with turnover intentions. This finding is in sync with the assertion that sport coaches who are emotionally exhausted feel that they are no longer able to give of themselves at a psychological level (Maslach et al., 1997) and are thereby more likely to withdraw from coaching. In conclusion, the results of this study showed that sport coaches experienced low levels of burnout. However, the small sample size limits the generalizations of the findings of this study to the wider South African population. Therefore, future studies should examine burnout among a larger sample of coaches in various sports (e.g. athletics, cricket, and soccer). Future research should also adopt longitudinal designs that could provide helpful information on the actual causes of burnout.

\section{REFERENCES}

Caccese, T. M., \& Mayerberg, C. K. (1984). Gender differences in perceived burnout of college coaches. Journal of Sport Psychology, 6, 279-288.

Dale, J., \& Weinberg, R. S. (1989). The relationship between coaches' leadership style burnout. The Sport Psychologist, 3, 1-13.

De Croon, E. M., Sluiter, J. K., Blonk, R. W., Broersen, J.P., \& Frings-Dresen, M. H. (2004). Stressful work, psychological job strain, and turnover: A two-year prospective cohort study of truck driver. Journal of Applied Psychology, 89(3), 442-454.

Everhart, C. B., \& Chelladurai, P. (1998). Gender differences in preferences for coaching as an occupation: The role of self-efficacy, valence, and perceived barriers. Research Quarterly for Exercise and Sport, 69(2), $188-200$.

Frey, M. (2007). College coaches' experiences with stress- "problem solvers" have problems too. The Sport Psychologist, 21, 38-57.

Gencay, S., \& Gencay, O. A. (2011). Burnout among Judo coaches in Turkey. Journal of Occupational Health, $53,365-370$.

Hjalm, S., Kentta, G., Hassmenan, P., \& Gustafsson, H. (2007). Burnout among elite soccer coaches. Journal of Sport Behavior, 30(4), 415-427.

International Council for Coaching Excellence and the Association of Summer Olympic International Federations (2012). International Sport Coaching Framework (Version 1.1). Champaign, IL: Human Kinetics.

Kamphoff, C. S. (2010). Bargaining with patriarchy. Research Quarterly For Exercise and Sport, 81(3), 360-372.

Kelley, B. C., Eklund, R. C., \& Ritter-Taylor, M. (1999). Stress and burnout among collegiate tennis coaches. Journal of Sport and Exercise Psychology, 21, 113-130.

Kilo, R. A., \& Hassmen, P. (2016) Burnout and turnover intentions in Australian coaches as related to organisational support and perceived control. International Journal of Sports Science and Coaching, 11(2), $151-161$.

Koustelios, A. (2010). Burnout among football coaches in Greece. Biology of Exercise, 6(1), 5-12.

Kubayi, N. A. (2015). Barriers and hindrances experienced by sport coaches in Gauteng Province (Unpublished Master's thesis). University of Johannesburg, Johannesburg.

Kubayi, N. A., Coopoo, Y., \& Morris-Eyton, H.F. (2015). Challenges faced by sport coaches in South Africa. African Journal for Physical, Health Education, Recreation and Dance, 21(3: 1), 724-732.

Kubayi, A., Toriola, A., \& Didymus, F. (2018). Development and initial validation of an instrument to assess stressors among South African sports coaches. Journal of Sports Sciences, 36(12), 1378-1384.

Leiter, M. P., \& Maslach, C. (2009). Nurse turnover: The mediating role of burnout. Journal of Nursing Management, 17(3), 331-339.

Maslach, C., \& Jackson, S. E. (1986). The Maslach Burnout Inventory. Palo Alto, CA: Consulting Psychologists Press. 
Maslach, C, Jackson, S. E., \& Leiter, M. P. (1996). The Maslach Burnout Inventory (3rd ed.). Palo Alto, CA: Consulting Psychologist Press.

Meyer, J. P., Allen, N. J., \& Smith, C. A. (1993). Commitment to organizations and occupations: Extension and test of a three-component conceptualization. Journal of Applied Psychology, 78(4), 538-551.

Pastore, D. L., \& Judd, M. R. (1993). Gender differences in burnout among coaches of women's athletic teams at 2-year colleges. Sociology of sport Journal, 10, 205-212.

Raedeke, T. D. (2004). Coach commitment and burnout: A one-year follow-up. Journal of Applied Sport Psychology, 16(4), 333-349.

Raedeke, T. D., Granzyk, T. L., \& Warren, A. (2000). Why coaches experience burnout: A commitment perspective. Journal of Sport and Exercise Psychology, 22, 85-105.

Sport Coach UK. (2013). Providing better support to club coaches: the approach taken by England athletics. Coachwise Ltd images.

Weinberg, R. S., \& Gould, D. (2007). Foundation of sport and exercise psychology (4th ed.). Champaign, IL: Human Kinetics.

Wuest, D. A. \& Fisette, J. (2012). Foundation of physical education, exercise science and sport (17th ed.). New York: Mcgraw-Hill.

Zhang, Y., \& Feng, X. (2011). The relationship between job satisfaction, burnout, and turnover intention among physicians from urban state-owned medical institutions in Hubei, China: A cross-sectional study. BMC Health Services Research, 11, 235. 